\title{
Persistent Primitive Trigeminal Artery: A Review
}

\section{Persistant PrimitifTrigeminal Arter: Bir Derleme}

\author{
Waleed AZAB ${ }^{1}$, Johnny DELASHAW ${ }^{2}$, Mohammed MOHAMMED ${ }^{3}$ \\ ${ }^{1}$ Ibn Sina Hospital, Department of Neurosurgery, Kuwait \\ ${ }^{2}$ Oregon Health \& Science University, Department of Neurosurgery, Portland, Oregon, USA \\ ${ }^{3} I$ Ibn Sina Hospital, Department of Neuroradiology, Kuwait
}

Correspondence address: Waleed AZAB / E-mail: waleedazab@hotmail.com

\begin{abstract}
The trigeminal artery is the largest of the fetal carotid-basilar anastomotic arteries, and it persists for the longest embryonic period. The artery usually involutes after the development of the posterior communicating artery. The exact causes of persistence of this primitive vessel into adulthood are not completely clear. Angiographic and anatomical descriptions of the various persistent trigeminal artery (PTA) configurations and their relation to the remainder of the cerebrovascular tree and the other surrounding structures have been reported. Persistent trigeminal artery can be associated with many other vascular anomalies and disorders including aneurysms, arteriovenous malformations and carotidcavernous fistulae. A thorough understanding of the anatomical and angiographic features of this persistent embryonic arterial channel is of utmost importance when making therapeutic decisions and embarking on surgical or endovascular intervention for any pertinent pathological condition. We review the embryology, angiographic features, microsurgical anatomy and associated vascular anomalies and disorders of the persistent trigeminal artery.
\end{abstract}

KEYWORDS: Aneurysm, Artery, Trigeminal

öz

Trigeminal arter, fetal karotik baziler anastomotik arterlerin en büyüklerinden biridir ve en uzun embriyonik dönem boyunca devam eder. Arter sıklıkla posterior komunikan arter geliştikten sonra küçülür. Bu primitif damarın yetişkin döneme kadar devam etmesinin nedenleri açık değildir. Çeşitli persistan trigeminal arter (PTA) konfigürasyonlarının anjiyografik ve anatomik tanıları ve serebrovasküler ağaç ve diğer çevre yapılarla ilişkileri bildirilmiştir. Persistan trigeminal arter anevrizma, arteriyovenöz malformasyonlar ve karotid-kavernöz fistül dahil olmak üzere birçok başka vasküler anomaliyle ilişkili olabilir. Persistan embriyonik arteriyel kanalın anatomik ve anjiyografik özelliklerinin tam olarak anlaşılması terapötik kararlar verirken ve ilgili herhangi bir patolojik durum açısından cerrahi veya endovasküler girişim düşünülürken çok önemlidir. Persistan trigeminal arter embriyolojisi, anjiyografik özellikleri, mikrocerrahi anatomisi ve ilişkili vasküler anomaliler ve bozuklukları gözden geçiriyoruz.

ANAHTAR SÖZCÜKLER: Anevrizma, Arter, Trigeminal

\section{INTRODUCTION}

The earliest description of the persistent trigeminal artery dates back to the year 1844 in the original work and drawings by Quain (64). About one century elapsed until the artery was angiographically demonstrated for the first time by Sutton in an article published in the British Journal of Radiology in 1950 (75). Persistent trigeminal artery (PTA) is the most common of the primitive carotid-basilar anastomoses that persist into adulthood, with an estimated incidence of 0.1 to $1.0 \%$ on cerebral angiograms $(17,20,36,39,47,52,67,70)$. A number of cases of PTA and its variants found at autopsy $(21,30,34,52,60,67,70,82)$, on cerebral angiograms $(2,6,7,17,27,35,73,85)$, and on MRI and MRA scans $(7,18,63)$ demonstrate the anatomy $(30,39,52,67)$ of this primitive anastomosis and its relationship to various vascular diseases $(1,16,19,20,25,30,36,44,47)$.

\section{I-EMBRYOLOGY}

The trigeminal artery is the largest of the fetal carotid-basilar anastomotic arteries, and it persists for the longest embryonic period, usually being obliterated by the $11.5-$ to $14-\mathrm{mm}$ embryonic stage $(1,16,20,35,39,52,59,67)$ (Figure 1).

In her remarkable treatise, "The development of the cranial arteries in the human embryo" published in 1948, Dorcas Hager Padget (59) wrote one of the most comprehensive reports of the development and involution of the trigeminal artery. The first evidence of the trigeminal artery is found in the 20 -somite $(3 \mathrm{~mm})$ embryo. The paired dorsal aortae have two definite branches at their junction with the first aortic arch: the primitive ICA, which extends to the optic vesicles at the forebrain, and the primitive trigeminal artery, which leaves the aorta just caudal to the carotid branch and arches dorsally toward the fifth nerve ganglion. The trigeminal artery at this stage supplies the cranial end of the primordial hindbrain channel whose proliferating endothelium gives rise to the bilateral longitudinal neural arteries (the future basilar artery) and the veins of the hindbrain. During the next stage (4-5 mm), the cranial end of each neural artery is supplied by the trigeminal artery. Development of the diencephalic and mesencephalic regions is accompanied by an extension of 


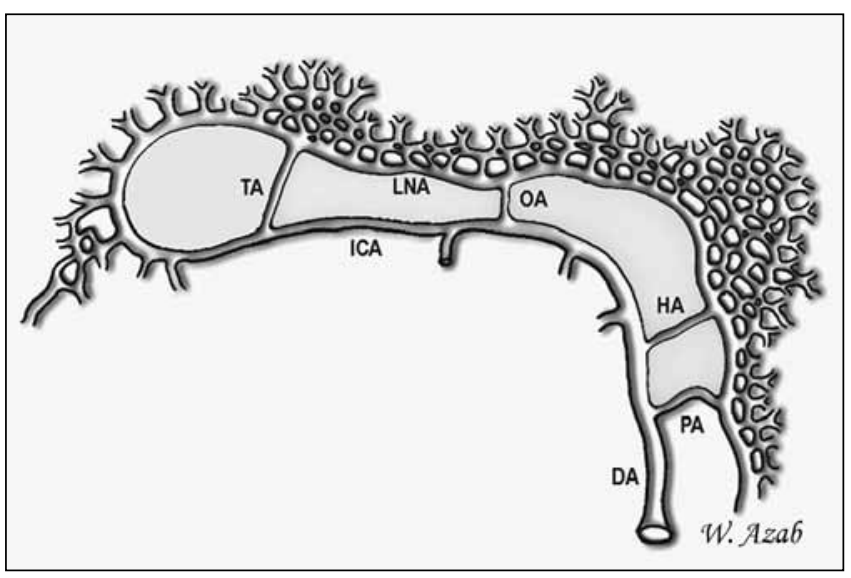

Figure 1: Embryology of the Trigeminal Artery. Trigeminal artey is the largest of the embryonic four carotid-basilar anastomotic arteries and persists for the longest fetal period.

the primary caudal division of the ICA, which becomes the definitive PCOA.

After the development of the PCoA, the trigeminal artery usually involutes. Other factors contributing to the elimination of the trigeminal anastomosis include a shifting in the relative position of the carotid and basilar ends of the anastomosis and the interposition of the basal sphenoid cartilage between the carotid and basilar ends during the 12- to 20-mm stages (59). Furthermore, Ohshiro et al. (52) published an autopsy study of an adult in whom PTA passed through a dural foramen located immediately medial to Meckel's cave and superolateral to Dorello's canal to enter the posterior fossa. The diameter of the PTA varied before, at, and after the dural foramen; measuring $4.0 \mathrm{~mm}$ before the foramen, $1.0 \mathrm{~mm}$ at the foramen, and $2.0 \mathrm{~mm}$ after the foramen. They speculated that the stenosis of the PTA at the foramen suggests that the dural foramen has a role in the regression of the PTA during the fetal stages of development.

The exact causes of persistence of a primitive vessel into adulthood, or non-resorption of a vessel once it reaches a critical size are not completely clear. It is thought that no rigid genetic programming exists in the development of the cerebral blood vessels, and that the momentary needs in the dynamic process of the developing brain continually reshape the vessels by formation, regression and anastomosis (74). Lasjaunias and Berenstein (38) suggest that the hemodynamic constraint imposed near a developing territory orientates that territory toward a particular vessel to maintain a hemodynamic balance. This results in the persistence of that vessel and, thus, an anatomic variant. Failure of regression of the trigeminal artery is thought by some authors to result from occlusion of the proximal portion of internal carotid artery in the fetus, resulting in an inevitable persistence of the trigeminal artery in order to maintain adequate blood supply to the forebrain through a retrograde transport of blood from the basilar to the carotid (56).

PTA variants are arteries that originate directly from the precavernous portion of the internal carotid artery but terminate as cerebellar arteries rather than anastomosing with the basilar artery (2). Persistence of the PTA with incomplete fusion of the longitudinal neural arteries may result in either a superior or an inferior cerebellar vessel arising anomalously from the cavernous ICA (28). This precludes a direct connection of the trigeminal artery with the BA and results in its termination as one of the cerebellar arteries (2).

\section{II- ANGIOGRAPHIC ANATOMY}

\section{Saltzman Classification}

In 1959, Saltzman (68) reported eight cases and proposed an angiographic classification for the PTA into two main types. In Saltzman Type 1, the PTA inserts into the basilar artery distal to the AICA but proximal to the SCA (2). The BA proximal to the insertion of the PTA may be hypoplastic, and the PCoA may be absent (44). In this type, the entire basilar artery system distal to the anastomosis is filled through the PTA which becomes the main supply to the distal BA, PCA, and SCA territories (44, 68). In Saltzman Type 2, the PTA inserts into the BA but mainly supplies the SCA's bilaterally (2). In this type, the PCAs receive their blood supply predominantly through patent PCoAs (44). The distal end of the basilar artery is angiographically poorly visualized (68).

The relative incidence of Saltzman type 1 and type 2 has been reported to be more or less equal (44). However, in a recent review utilizing 3.0 T MRA in 25 cases of PTA the incidence of type I was $24 \%$ while that for type II was only $16 \%$ (10).

Saltzman (68) classified one case as a combination of the two types; PCoA supplied the PCA on the same side of the PTA and the PTA supplied both SCAs and the PCA on the opposite side. A similar case was reported in 1974 by Parkinson and Shields (60) who demonstrated both angiographic and anatomic features of a PTA filling both SCAs and the contralateral PCA with a fetal PCOA on the same side of the PTA supplying the ipsilateral PCA; a description which corresponds to a combination of the Saltzman Types I and II. Many Saltzman variants, sometimes referred to as Saltzman type 3, have subsequently been described $(12,41,78)$. The PTA variant directly joins into a cerebellar artery (42). It arises from the ICA and terminates directly without anastomosing with BA as SCA (Saltzman Type 3a), AICA (Saltzman Type3b), or PICA (Saltzman Type3c) $(2,8,15,28,50,51,71,78,79)$. Among the PTA variants, the majority fall under Type $3 \mathrm{~b}$ with termination at the AICA; with types $3 a$ and $3 c$ being extremely rare in the literature $(2,65)$. It is thought that as the PTA is closer to the origin of the AICA than to the origin of the PICA during embryological development, anterior vessels are more likely to originate anomalously from the carotid artery than are the posterior ones (28). PTA variants are uncommon (2) and are reported to have an incidence of approximately $0.18 \%$ (73).

\section{III- SURGICAL ANATOMY}

\section{- ORIGIN AND INITIAL COURSE}

A PTA may originate from left (67) or right (74) ICA. The most common sites of origin for a PTA are the posterior bend or 
lateral wall of the intracavernous carotid artery $(52,60,67)$. In one autopsy case, the PTA originated from the posterior bend of the cavernous ICA to run posteriorly in the posterolateral space of the cavernous sinus (52). Salas et al. (67) reported the vessel to originate from the posterolateral aspect of the ascending (posterior vertical) cavernous segment of the ICA just medial to the sixth nerve to make an acute inferolateral angle and a course below the sixth nerve immediately at the point of leaving the ICA to exit the cavernous sinus by piercing the reticular layer of the sinus wall, forming a posterior loop around the sphenopetrous (Gruber's) ligament then to run in the medial wall of Meckel's cave. In some reports, however, the PTA arose from the medial wall of the cavernous ICA $(70,74)$. Suttner et al. (74) found a PTA arising from the superomedial portion of the distal horizontal segment of the intracavernous carotid artery, coursing medially and immediately posteroinferiorly, to continue between the posterior bend of the carotid artery laterally and the pituitary gland medially passing the junction of the posterior clinoid process and the pituitary gland to exit the posterior wall of the cavernous sinus.

\section{- RELATION TO ABDUCENT \& TRIGEMINAL AFTER LEAVING CS}

In relation to the dorsum sellae, approximately 50 to $59 \%$ of all cases of PTA penetrate the sella turcica, course along their own groove, perforate the dura near the clivus, and then join the basilar artery with thinning of the sellar floor and abnormalities of the dorsum sellae being a frequent finding while in the remaining 41 to $50 \%$ of cases, the PTA runs lateral to the sella turcica $(39,52)$. In 1993, Ohshiro et al. (52) reviewed the relation of PTA to the dorsum sellae in 22 of 25 autopsy cases described up to the time of their writing. Analyzing the anatomical data of these cases, they classified PTA into two types: a medial type in which the artery runs through the dorsum sellae and perforates the dura mater near the clivus and a lateral type in which the artery runs between the sensory root of the trigeminal nerve and the lateral side of the sella to penetrate the dura mater medial to Meckel's cave. These authors also described one case of their own which was classified as lateral type, and the vessel was passing through a dural foramen clearly different from and located immediately medial to Meckel's cave; the foramen was superolateral to Dorello's canal and lateral to the petroclinoid ligament. Inoue et al. (12) reported both the trigeminal and abducens nerves to run lateral to the PTA in one specimen. Tulsi and Locket (83) reported one case in which the trigeminal artery had a medial course crossing below the level of the pituitary fossa and piercing the dura of the dorsum sellae; in two other cases in their study, the PTA had a course lateral to the abducens nerve and pierced the dura of the posterior fossa just medial to the sensory root of the trigeminal nerve.

\section{SALAS CLASSIFICATION}

Salas et al. (67) classified the PTA by its relationship to the abducens nerve, distinguishing a lateral (petrosal) and a medial (sphenoidal) variations. When the trigeminal artery courses lateral to the $\mathrm{VI}^{\text {th }}$ cranial nerve, the artery arises from the posterolateral aspect of the C4 segment of the cavernous carotid and crosses underneath the nerve which may be displaced superiorly by the PTA. This petrosal variation of the PTA pierces the dura just medial to the sensory root of the trigeminal nerve. When the PTA courses medial to the abducens nerve, the artery arises from the posteromedial aspect of the C4 segment of the cavernous carotid artery and pierces the dura of the dorsum sellae (sphenoid variation). Clinically, the lateral variant may be associated with brainstem ischemia, ophthalmoplegia, and trigeminal neuralgia. The medial variant can be associated with posterior fossa symptoms secondary to a steal phenomenon. The surgeon should also be aware of a medial PTA during a transsphenoidal surgery to avoid severe hemorrhage (7).

\section{- ENTRANCE INTO BASILAR ARTERY (Figure 2)}

PTA joins the BA between the SCA and the AICA $(52,74)$. In one anatomical report, the vessel completed its course to the basilar artery with a communication $2 \mathrm{~mm}$ inferior to the left superior cerebellar artery. The length of the artery between the dural (trigeminal) ring and the basilar artery was $22 \mathrm{~mm}$, and the overall length from the carotid to the basilar artery was $33 \mathrm{~mm}$. The mean diameter after the dural ring was 3.5 $\mathrm{mm}$ (67).

\section{- BRANCHES}

Branches from a PTA in adult anatomic specimens have been described. These include pontine perforators and branches to trigeminal ganglion, the meningohypophyseal trunk and its branches and cerebellar arteries.

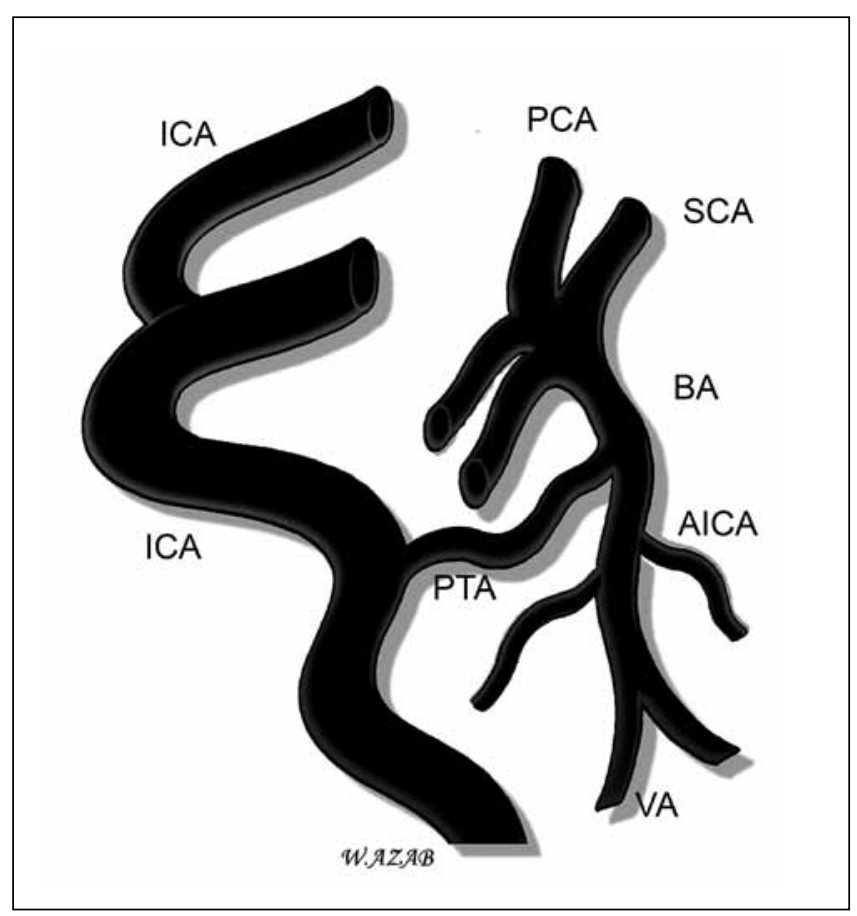

Figure 2: Schematic representation of entrance of the PTA to BA. PTA joins the BA between the SCA and the AICA. 


\section{A-Pontine Perforators and Branches to the Trigeminal Ganglion:}

Khodadad (34) demonstrated pontine branches from the trunk of the PTA in brains of 4-,6-, and 8-month fetuses. He suggested that the PTAs might become of functional and clinical significance if they persisted. Ohshiro et al. (52) reported a case in which two branches from the cisternal portion of the PTA were present. One branch sent a feeding artery to the left trigeminal nerve root and a perforating artery to the pons. The other branch perforated directly into the pons. Salas et al. (67) described four pontine perforating branches originating from the intradural segment of the artery which were $7,10,11$, and $17 \mathrm{~mm}$ distal from the dural ring in the wall of Meckel's cave. It is highly probable that these branches are functioning vessels in the brain stem even in adult cases; with occlusion of the PTA leading to the ischemic lesions in the brainstem $(52,37)$.

\section{B-Cerebellar Arteries:}

Arakawa et al. (3) reported one case in which the AICA arose from the internal carotid artery passing medial to the abducens nerve. This artery gave off a small branch communicating to the basilar artery, passed lateral to the trigeminal nerve root, and continued backward to the dorsal surface of the cerebellum; AICA is thus considered a branch of the PTA. Four arterial twigs branched from this artery at the ventral surface of the brain stem, two twigs distributed to the medial surface of the trigeminal nerve root, the third twig distributed to the lateral surface of the trigeminal nerve root and the fourth twig directly connected with the basilar artery. Finally, the main trunk of the artery wound backward to pass lateral to the trigeminal nerve root and distributed to the anteroinferior surface of the cerebellum. In the other case by these authors, PTA gave off medial and lateral arterial branches to pour into the basilar artery. The medial branch was a pontine branch supplying the basal pons. The lateral branch passed caudally to give off a twig to the lateral surface of the trigeminal nerve root. This arterial branch passed medial to the trigeminal nerve root to divide into two lateral and medial arterial twigs. The lateral twig, which traversed laterally, connected with the AICA. The medial twig passed medialwards to give off a nutrient artery to the ventral surface of the pons near the facial nerve root. The medial twig gave off some pontine branches and finally anastomosed with the lateral surface of the basilar artery.

\section{C-Meningohypophyseal Trunck and its Branches:}

Lie (41) described MHT branching off at the origin of the PTA on cerebral angiograms. In a review of various anatomic descriptions, the origins of the PTA and the MHT were found to be common or separate, and the PTA might give rise to vessels normally arising from the MHT (67). Inoue et al. (30) described a specimen in which the dorsal meningeal, tentorial, and inferior hypophyseal arteries, usually branches of the MHT, were arising from the PTA as individual branches. In the case reported by Ohshiro and colleagues (52) the MHT and the ACS branched off at the origin of the PTA. They suggested that the PTA, the MHT, and the ACS might be closely linked in the embryo. Suttner et al. (74) described a case in which PTA gave off two branches: the inferior hypophyseal artery medially and the dorsal meningeal artery to the clivus inferolaterally. The capsular artery of McConnell arose from the inferomedial portion of the intracavernous carotid artery, and crossed below the PTA in its course to the pituitary capsule. The tentorial artery arose directly from the intracavernous carotid artery at its posterior bend. They suggested that the medial (sphenoidal) variation presented by Salas and colleagues (67) may represent a different carotid-basilar anastomosis from the PTA and that the MHT is the possible remnant of this vessel. On the other hand, they considered the lateral (petrosal) variation the true PTA because it can provide blood supply both to the brainstem and to the trigeminal ganglion. Dwight Parkinson pointed out that the MHT may be a remnant of an earlier carotid basilar connection above the sixth nerve distinct from the true PTA below the sixth nerve (52). Parkinson and Shields (60) analyzed the differences between the PTA and MHT and stressed their separate origins, emphasizing that the MHT has three main branches and that the PTA has none.

\section{- ASSOCIATED ANOMALIES IN CADAVERIC STUDIES}

There is a multitude of anatomical variations and anomalies associated with PTA including ipsilateral fetal PCoA $(60,74)$, bilateral fetal PCAs (Saltzman Type II) (30), hypoplastic BA proximal to the connection with the PTA $(60,82)$, as well as hypoplastic VAs below the junction with the PTA (60). BA hypoplasia proximal to its anastomosis with the PTA is frequently associated with this type of vascular anomaly (60), and is probably caused by a poor-flow-related stimulus for further development (7). Other anomalies include a duplicated SCA and hypoplastic AICA (60), bilateral absence of PICAs (52), fenestrated oculomotor nerve around the PCA (60) and a subdural course of the PTA over the clivus within a dedicated dural sleeve or canal before becoming intradural and anastomosing with the BA has been described in one specimen (60). In some reports, however no other anomalies of the cerebral vessels were noted; both PCoAs had a normal, nonfetal pattern on both sides $(67,83)$.

\section{IV-ASSOCIATED CLINICAL CONDITIONS}

\section{(1) Cerebrovascular anomalies}

These include ectasia and fenestration of the ACA (81), infraoptic course of $A_{1}$ segment of ACA (84), absence of the CCA (66), absence of both ICAs (27), occluded ICA (31), hypoplastic BA and VA $(5,58,84)$, bilateral occlusion of VA (31), primitive otic artery (31) and PHACE syndrome (62).

\section{(2) Aneurysms (Figures 3 and 4A, B)}

Davis et al. (14) first reported an aneurysm of the PTA in 1956. Cloft et al. (11) reported a $3 \%$ prevalence of cerebral aneurysms with PTA in their series of 34 patients, which is similar to the prevalence of intracranial aneurysms in the general population. Others reported that approximately 13.8 to $27.8 \%$ of patients with PTA also had intracranial aneurysms $(10,53)$. A more recent analysis of 103 PTAs detected in 16,415 
MRAs reported an incidence of 3.9\% of cerebral aneurysms in patients harboring a PTA (58). Cerebral aneurysms associated with PTA have been reported to occur in relation to the bifurcations formed by the PTA and either the ICA $(40,46,57)$ or the BA $(45,86)$. Aneurysms may also be present in other locations of the cerebral circulation (23) including cavernous ICA (40), PCA (69), PCoA $(5,24,53)$, ACoA $(49,84)$ and BA-SCA (29). Aneurysms of the PTA itself are quite rare $(9,20)$, and arise either from the trunk of a PTA (76) or a PTA variant (26). Clinically, patients may present with sixth nerve palsy $(46,57)$, subarachnoid hemorrhage (76) or carotid cavernous fistula secondary to rupture of these aneurysms (11) Direct surgical clipping (76), endovascular coiling $(46,57)$ or stent-assisted coiling (48) have been employed to treat these aneurysms. important in the supply of the hindbrain, PTA patency should be preserved if possible during surgery (76).

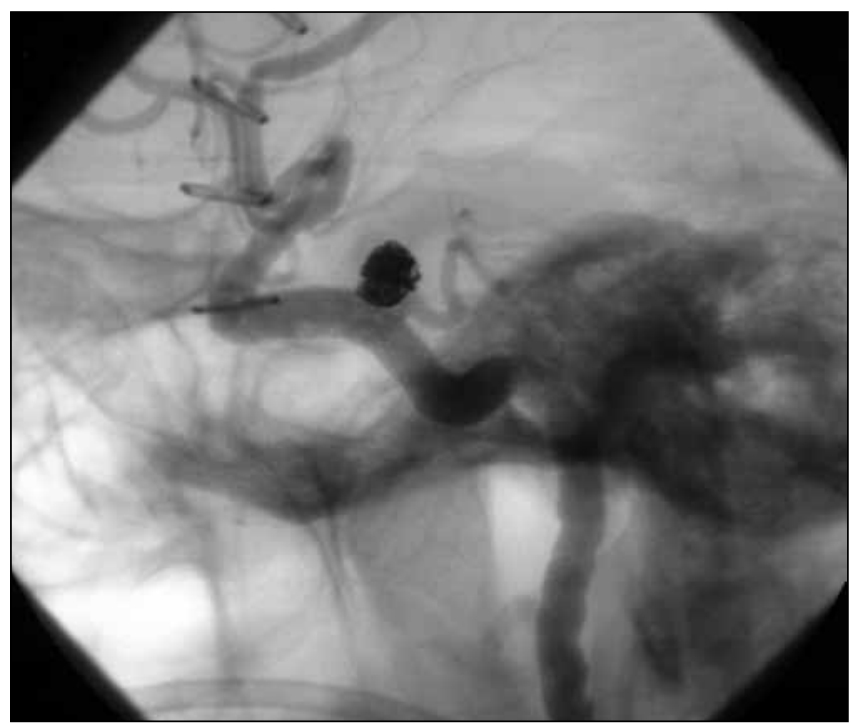

Figure 3: Cavernous ICA-PTA bifurcation aneurysm coiled after a failed surgical clipping.

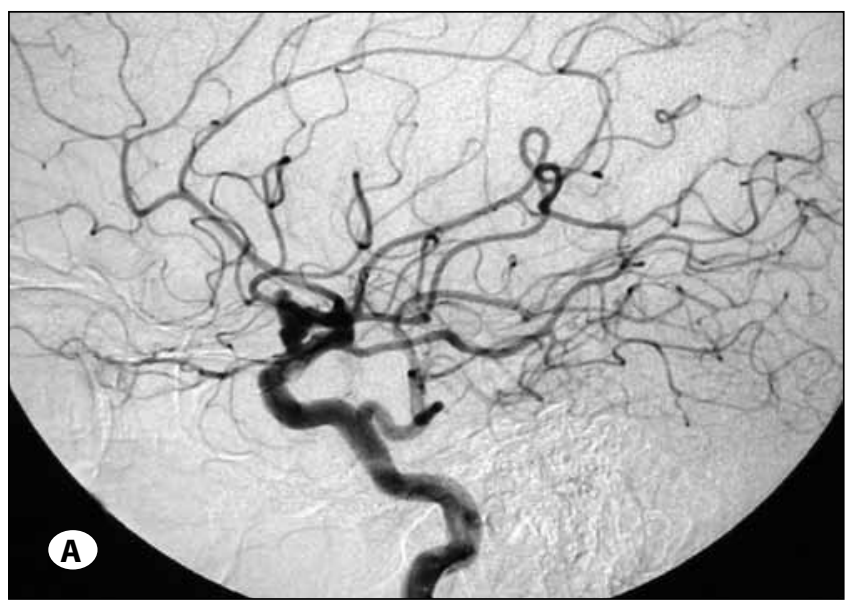
As the perforating arteries originating from the PTA may be

Ikushima et al. (29) were the first to treat an aneurysm endovascularly via a PTA. These authors reported occlusion of a saccular aneurysm of the right BA-SCA with Guglielmi detachable coils by advancing a microcatheter through the PTA in their patient in whom both VAs and BA proximal to the junction with the PTA were hypoplastic. Similarly, Schlamann and colleagues (69) reported treatment of an acutely ruptured wide-necked PCA aneurysm using Guglielmi detachable coils and remodeling technique through a carotid artery approach via a PTA to selectively catheterize the aneurysm. In patients with hypoplastic VAs and a PTA, this approach may represent an alternative for selective embolization of posterior circulation aneurysms $(29,69)$.

$\mathrm{Li}$ et al. (40) for the first time reported opening of a PTA associated with contrast filling of a cavernous ICA aneurysm 4 months after its primary treatment with balloon occlusion of the ICA. They concluded that the possibility of contrast filling of aneurysms via potential PTA should be considered in the event of an aneurysm with parent artery occlusion.

\section{(3) Vertebrobasilar insufficiency and brain stem ischemia}

The pathogenesis of vertebrobasilar insufficiency in patients with PTA may be attributed to microemboli originating from an atherosclerotic carotid artery owing to the presence of direct communication between the anterior and posterior circulations (72), or to occlusion of the PTA leading to a decreased blood flow in the basilar artery (32).

\section{(4) Carotid-cavernous fistula}

Carotid-cavernous fistula $(13,55)$ and PTA-cavernous sinus fistula (80) may develop either spontaneously or after a traumatic event and are best treated with endovascular occlusion techniques $(4,43)$.

\section{(5) Miscellaneous conditions}

PTA has been reported in the context of NF-1 (22), Klippel-Feil syndrome (61), Moyamoya disese (35) as well as infratentorial $(49,54)$ and supratentorial AVMs (77).

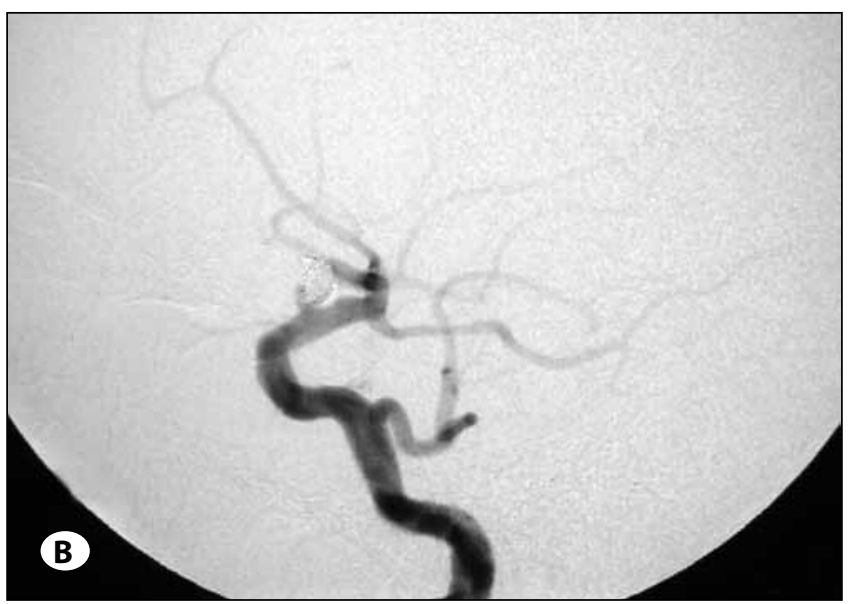

Figure 4: Persistent trigeminal artery and an associated ruptured PCoA aneurysm before (A) and after (B) endovascular coiling. Note the fetal configuration of the PCoA. 


\section{CONCLUSION}

Persistent trigeminal artery (PTA) is the most common of the primitive carotid-basilar anastomoses that persist into adulthood. It may be associated with other cerebrovascular variants and disorders that may necessitate treatment. PTA has important anatomical and clinical aspects that should be taken in consideration when managing lesion in its vicinity.

\section{ABBREVIATIONS}

$A C A$ Anterior cerebral artery, $A C O A$ Anterior communicating artery, ACS Artery of the inferior cavernous sinus, AICA Anterior inferior cerebellar artery, BA Basilar artery, CCA Common carotid artery, DA Dorsal aorta, HA Hypoglossal artery, ICA Internal carotid artery, , LNA Longitudinal neural artery MHT Meningohypophyseal trunk, NF-1 Neurofibromatosis type 1 , $O A$ Otic artery, PCA Posterior cerebral artery, PCoA Posterior communicating artery, PHACE Posterior fossa malformations, Hemangiomas, Arterial anomalies, Coarctation of the aorta and other cardiac defects, and Eye abnormalities. PICA Posterior inferior cerebellar artery, PTA Persistent trigeminal artery, SCA Superior cerebellar artery, VA Vertebral artery.

\section{REFERENCES}

1. Ahmad $Y$, Tominaga $T$, Suzuki $M$, Ogawa A, Yoshimoto $\mathrm{T}$ : Primitive trigeminal artery associated with cavernous aneurysm. Case report. Surg Neurol 41:75-79, 1994

2. Ali S, Radaideh MM, Shaibani A, Russell EJ, Walker MT: Persistent trigeminal artery terminating in the posterior inferior cerebellar artery: Case report. Neurosurgery 62: E746-748, 2008

3. Arakawa T, Koizumi M, Terashima T, Honma S, Kawai K, Kodama K, Miki A: Two anatomical autopsy cases of direct communication between a persistent primitive trigeminal artery and an anterior inferior cerebellar artery. Ann Anat 189:489-498, 2007

4. Asai K, Hasuo K, Hara T, Miyagishima T, Terano N: Traumatic persistent trigeminal artery-cavernous sinus fistula treated by transcatheter arterial embolization: A case report. Interv Neuroradiol 16:93-96, 2010

5. Başkaya MK, Roberts R, Rivera E, Nanda A: Persistent primitive trigeminal artery associated with posterior communicating artery aneurysm and hypoplastic vertebral artery. Surg Radiol Anat 23:169-171, 2001

6. Binet EF, Young RF: Bilateral persistent trigeminal arteries: Case report. J Neurosurg 47:619-622,1977

7. Boyko OB, Curnes JT, Parker DL: MRI of basilar artery hypoplasia associated with persistent primitive trigeminal artery. Neuroradiology 38:11-14, 1996

8. Chambers A, Lukin A: Trigeminal artery connection to the posterior inferior cerebeblar arteries. Neuroradiology 9: 121-123, 1975

9. Chan D, Boet R, Yu S, Poon WS: Trispan-assisted coiling of a wide-necked persistent trigeminal artery aneurysm. Acta Neurochir (Wien) 146:87-88, 2004
10. Chen YC, Li MH, Chen SW, Hu DJ, Qiao RH: Incidental findings of persistent primitive trigeminal artery on 3-Dimensional Time-of-Flight magnetic resonance angiography at 3.0 T: An analysis of 25 cases. J Neuroimaging 21(2):152-158, 2010 doi: 10.1111/j.1552-6569.2010.00472

11. Cloft HJ, Razack N, Kallmes DF: Prevalence of cerebral aneurysms in patients with persistent primitive trigeminal artery. J Neurosurg 90:865-867, 1999

12. Cobb SR, Hieshima GB, Mehrhger CM, Grinnell VS, Pribram HW: Persistent trigeminal artery variant: Carotid-anterior inferior cerebellar artery anastamosis. Surg Neurol 19: 263-266,1983

13. Cook BE Jr, Leavitt JA, Dolan JW, Nichols DA: Carotid cavernous fistula associated with persistent primitive trigeminal artery. $J$ Neuroophthalmol 20:264-265, 2000

14. Davis RA, Wetzel N, Davis L: An analysis of the results of intracranial vascular lesions by carotid artery ligation. Ann Surg 143: 641-648,1956

15. Dilenge D: The internal carotid artery. In: Newton TH, Potts DG, (eds), Radiology of the Skull and Brain. St Louis: Mosby, 1974:1202-1245

16. Enomoto T, Sato A, Maki Y: Carotid-cavernous sinus fistula caused by rupture of a primitive trigeminal artery aneurysm. Case report. J Neurosurg 46:373-376, 1977

17. Fields WS: The significance of persistent trigeminal artery. Carotid-basilar anastomosis. Radiology 91:1095-1101,1968

18. Fortner AA, Smoker WR: Persistent primitive trigeminal artery evaluated by MR imaging and angiography. J Comput Assist Tomogr 12:847-850,1988

19. Filatov luM, Eliava ShSh, Zolotukhin SP, Talanov AB: The persistent trigeminal artery in vascular brain diseases. Zh Vopr Neirokhir Im N N Burdenko 2:3-6,1998 (Article in Russian)

20. Freitas PE, Aquini MG, Chemale I: Persistent primitive trigeminal artery aneurysm. Surg Neurol 26:373-374, 1986

21. Fujii Y, Kawasaki S, Abe H, Yamada M, Yoshida Y: An autopsy case of a persistent primitive trigeminal artery aneurysm. No Shinkei Geka 16:181-186, 1988 (Article in Japanese)

22. Fujimoto M, Nakahara I, Tanaka M, Iwamuro $Y$, Watanabe $\mathrm{Y}$, Harada K: Multiple intracranial aneurysms and vascular abnormalities associated with neurofibromatosis type 1: A case report. No Shinkei Geka 32:355-359, 2004 (Article in Japanese)

23. George $A E$, Lin JP, Morantz RA: Intracranial aneurysm on a persistent primitive trigeminal artery. Case report. J Neurosurg 35: 601-604, 1971

24. Gimeno Peribáñez MJ, Pina Leita Jl, Lasierra Díaz R, Carro Alonso B: Persistent primitive trigeminal artery associated to aneurysm of the posterior communicating artery: A case report. Radiologia 49:351-354, 2007 (Article in Spanish)

25. Guglielmi G, Viñuela F, Dion J, Duckwiler G, Cantore G, Delfini R: Persistent primitive trigeminal artery-cavernous sinus fistulas. Report of two cases. Neurosurgery 27:805-809, 1990

26. Hanabusa K, Murao K, Morikawa A, Taki W, Waga S: Endovascular treatment for a ruptured persistent trigeminal artery variant aneurysm on the distal portion. Case report. Neurol Med Chir (Tokyo) 40:637-640, 2000 
27. Hattori T, Kobayashi H, Inoue S, Sakai N: Persistent primitive trigeminal artery associated with absence of internal carotid artery. Surg Neurol 50:352-355, 1998

28. Haughton VM, Rosenbaum AE, Pearce J: Internal carotid artery origins of the inferior cerebellar arteries. AJR Am J Roentgenol 130:1191-1192, 1978

29. Ikushima I, Arikawa S, Korogi Y, Uehara H, Komohara Y, Takahashi M: Basilar artery aneurysm treated with coil embolization via persistent primitive trigeminal artery. Cardiovasc Intervent Radiol 25:70-71, 2002

30. Inoue T, Rhoton AL Jr, Theele D, Barry ME: Surgical approaches to the cavernous sinus: A microsurgical study. Neurosurgery 26:903-932, 1990

31. Karasawa J, Kikuchi H, Furuse S, Sakaki T, Yoshida Y, Ohnishi $\mathrm{H}$ : Bilateral persistent carotid- basilar anastomoses. Am J Roentgenol 127:1053-1056, 1976

32. Kato $Y$, Nagoya H, Furuya D, Deguchi I: Locked-in syndrome due to bilateral cerebral peduncular infarctions with occlusion of persistent primitive trigeminal artery. Rinsho Shinkeigaku 47:601-604, 2007 (Article in Japanese)

33. Kerber CW, Manke W: Trigeminal artery to cavernous sinus fistula treated by balloon occlusion. Case report. J Neurosurg 58:611-613, 1983

34. Khodadad G: Persistent trigeminal artery in the fetus. Radiology 121:653-656, 1976

35. Komiyama M, Kitano S, Sakamoto H, Shiomi M: An additional variant of the persistent primitive trigeminal artery: Accessory meningeal artery-Antero-superior cerebellar artery anastomosis associated with moyamoya disease. Acta Neurochir (Wien) 140:1037-1042, 1998

36. Kwak R, Kadoya S: Moyamoya disease associated with persistent primitive trigeminal artery: Report of two cases. J Neurosurg 59:166-171, 1983

37. Kwon JY, Lee EJ, Kim JS: Brainstem infarction secondary to persistent trigeminal artery occlusion: Successful treatment with intravenous rt-PA. Eur Neurol 64:311, 2010

38. Lasjaunias $P$, Berenstein $A$ : The internal maxillary system. In: Lasjaunias P, Berenstein A, (eds), Surgical Neuroangiography. New York: Springer-Verlag, 1987:33-121

39. Lee KS, Kelly DL Jr: Intrasellar persistent trigeminal artery associated with pituitary adenoma: Case report. J Neurosurg 70:271-273, 1989

40. Li MH, Li WB, Pan YP, Fang C, Wang W: Persistent primitive trigeminal artery associated with aneurysm: Report of two cases and review of the literature. Acta Radiol 45:664-668, 2004

41. Lie TA: Congenital Anomalies of the Carotid Arteries. Amsterdam: Excerpta Medica, 1968:52-70

42. Luh GY, Dean BL, Tomsick TA, Wallace RC: The persistent fetal Carotid-Vertebrobasilar anastomoses. AJR 172:1427-1432, 1999

43. Matosevic B, Kiechl S, Werner P, Hefel C, Willeit J, Chemelli A: A case of a traumatic trigeminal-cavernous fistula occluded by coil embolization. J Neuroimaging 21(3):280-282, 2011 doi: $10.1111 /$ j.1552-6569.2010.00528.x
44. McKenzie JD, Dean BL, Flom RA: Trigeminal-cavernous fistula: Saltzman anatomy revisited. Am J Neuroradiol 17: 280-282,1996

45. Menkü A, Akdemir H, Tucer B, Kurtsoy A: Ruptured aneurysm associated with persistent primitive trigeminal artery: Report of a case with three dimensional CT angiographic evaluation. Turkish Neurosurgery 14:21-24, 2004

46. Memis A, Demirpolat G, Biceroglu S: Persistent trigeminal artery aneurysm: Treatment with coil embolization. J Vasc Interv Radiol 18:459-461, 2007

47. Merry GS, Jamieson KG: Operative approach to persistent trigeminal artery producing facial pain and diplopia: Case report. J Neurosurg 47:613-618, 1977

48. Mohammed MI, Sandhu JS, Wakhloo AK: Stent-assisted coil placement in a wide-necked persistent trigeminal artery aneurysm with jailing of the trigeminal artery: A case report. Am J Neuroradiol 23:437-441, 2002

49. Nakai Y, Yasuda S, Hyodo A, Yanaka K, Nose T: Infratentorial arteriovenous malformation associated with persistent primitive trigeminal artery-case report. Neurol Med Chir (Tokyo) 40:572-574, 2000

50. Nishio A, Nishijima Y, Komiyama M, Hara M: Primitive trigeminal artery variant aneurysm treated with Guglielmi detachable coils: Case report. Neurol Med Chir (Tokyo) 41:446- 449, 2001

51. Nutik S, Dilenge D: Carotid anterior cerebral artery anastomosis. J Neurosurg 44:378-382, 1976

52. Ohshiro S, Inoue T, Hamada $\mathrm{Y}$, Matsuno $\mathrm{H}$ : Branches of the persistent trigeminal artery-An autopsy case. Neurosurgery 32:144-148, 1993

53. Ohta H, Genmoto T, Yokota A: Multiple cerebral aneurysms and a contralateral occluded internal carotid artery associated with persistent primitive trigeminal artery. No Shinkei Geka 32:1045-1048, 2004 (Article in Japanese)

54. Ohtakara K, Kuga Y, Murao K, Kojima T, Taki W, Waga S: Posterior fossa arteriovenous malformation associated with persistent primitive trigeminal artery-case report. Neurol Med Chir (Tokyo) 40:169-172, 2000

55. Oka Y, Sadamoto K, Tagawa M, Kumon Y, Sakaki S, Fujita M: Transvenous embolization of carotid-cavernous sinus fistula associated with a primitive trigeminal artery case report. Neurol Med Chir (Tokyo) 40:61-64, 2000

56. Okuno T, Nishiguchi T, Hayashi S, Miyamoto K, Terashita T, Itakura $\mathrm{T}$, Moriwaki $\mathrm{H}$, Komai $\mathrm{N}$ : A case of carotid superior cerebellar artery anastomosis associated with bilateral hypoplasia of the internal carotid artery represented as the rupture of posterior cerebral artery-posterior communicating artery aneurysm. No Shinkei Geka 16:1211-1217, 1988 (Article in Japanese)

57. Onizuka M, Kazekawa K, Tsutsumi M, Kodama T, Aikawa $\mathrm{H}_{\text {, }}$ Ikou M, Tomokiyo M, Matsubara S, Nii K, Tanaka A: Hyperform remodeling balloon for the balloon occlusion test of persistent primitive trigeminal artery aneurysm - case report. Neurol Med Chir (Tokyo) 46:541-543, 2006 
58. O'uchi E, O'uchi T: Persistent primitive trigeminal arteries (PTA) and its variant (PTAV): Analysis of 103 cases detected in 16,415 cases of MRA over 3 years. Neuroradiology 52: 1111-1119, 2010

59. Padget DH: Development of cranial arteries in human embryo. Contrib Embryol 32:205-262,1948

60. Parkinson D, Shields CB: Persistent trigeminal artery: Its relationship to the normal branches of the cavernous carotid. J Neurosurg 40:244-248, 1974

61. Paksoy Y, Seker M, Kalkan E: Klippel-Feil syndrome associated with persistent trigeminal artery. Spine (Phila Pa 1976) 29(9):E193-196, 2004

62. Pascual-Castroviejo I, Alvarez-Linera J, Coya J, Viaño J, Pascual-Pascual SI, Velázquez-Fragua R, López-Gutiérrez JC: Pascual-Castroviejo type II syndrome (P-CIIS). Importance of the presence of persistent embryonic arteries. Childs Nerv Syst 27(4):617-625, 2011 doi: 10.1007/s00381-010-1242-7

63. Piotin M, Miralbes S, Cattin F, Marchal H, Amor-Sahli M, Moulin T, Bonneville JF: MRI and MR angiography of persistent trigeminal artery. Neuroradiology 38:730-733,1996

64. Quain R: The Anatomy of the Arteries of the Human Body and Its Applications to Pathology and Operative Surgery, with a Series of Lithographic Drawings. London: Taylor and Walton, 1844

65. Raphaeli G, Bandeira A, Mine B, Brisbois D, Lubicz B: A rare variant of persistent trigeminal artery: Cavernous carotidcerebellar artery anastomosis- a case report and a systematic review. Cerebellum 8:445-447, 2009

66. Rossitti S, Raininko R: Absence of the common carotid artery in a patient with a persistent trigeminal artery variant. Clin Radiol 56:79-81, 2001

67. Salas E, Ziyal IM, Sekhar LN, Wright DC: Persistent trigeminal artery: An anatomic study. Neurosurgery 43:557-562,1998

68. Saltzman GF: Patent primitive trigeminal arteries studied by cerebral angiography. Acta Radiol 51:329-336,1959

69. Schlamann M, Doerfler A, Schoch B, Forsting M, Wanke I: Balloon-assisted coil embolization of a posterior cerebral artery aneurysm via a persistent primitive trigeminal artery: Technical note. Neuroradiology 48:931-934, 2006

70. Schmid AH: Persistent trigeminal artery. An autopsy report. Neuroradiology 7:173-175,1974

71. Scotti G: Anterior inferior cerebellar artery originating from the cavernous portion of the internal carotid artery. Radiology 116:93-94,1975

72. Shioya H, Kikuchi K, Suda Y, Shindo K: Persistent primitive trigeminal artery presenting with Weber's syndrome: Report of a case with three-dimensional CT angiographic evaluations. No To Shinkei 52:315-319, 2000 (Article in Japanese)
73. Siqueira $M$, Piske $R$, Ono $M$, Marino $R$ Jr: Cerebellar arteries originating from the internal carotid artery. AJNR Am J Neuroradiol 14:1229-1235, 1993

74. Suttner N, Mura J, Tedeschi H, Ferreira M, Wen $H$, de Oliveira $\mathrm{E}$, Rhoton AL Jr: Persistent trigeminal artery: A unique anatomic specimen- analysis and therapeutic implications. Neurosurgery 47:428-434, 2000

75. Sutton D: Anomalous carotid-basilar anastomosis. Br J Radiol 23:617-619, 1950

76. Takase T, Tanabe H, Kondo A, Nonoguchi N, Tane K: Surgically treated aneurysm of the trunk of the persistent primitive trigeminal artery-case report. Neurol Med Chir (Tokyo) 44:420-423, 2004

77. Talanov AB, Filatov luM, Eliava ShSh, Novikov AE, Kulishova laG: Arteriovenous malformation of septum pellucidum in combination with persistent trigeminal neuralgia. Zh Vopr Neirokhir Im N N Burdenko 4:50-53, 2009 (Article in Russian)

78. Teal JS, Raumbaugh CL, Bergeron AT, Scanban AL, Segall $H$ : Persistent carotid-superior cerebellar artery: A variant of persistent trigeminal artery. Radiology 103:335-341, 1972

79. Teal JS, Rumbaugh $\mathrm{CL}$, Segall $\mathrm{H}$, Bergeron AT: Anomalous branches of the internal carotid artery. Radiology 106: 567-573, 1973

80. Tokunaga K, Sugiu K, Kameda M, Sakai K, Terasaka K, Higashi T, Date I: Persistent primitive trigeminal artery-cavernous sinus fistula with intracerebral hemorrhage: Endovascular treatment using detachable coils in a transarterial doublecatheter technique. Case report and review of the literature. J Neurosurg 101:697-699, 2004

81. Tran-Dinh H, Dorsch N, Soo Y: Ectasia and fenestration of the anterior cerebral artery associated with persistent trigeminal artery: Case report. Neurosurgery 31:125-128,1992

82. Tschabitscher $M$, Weber M, Georgopoulos M: The persistent trigeminal artery and its topographical relations. Acta Anat (Basel) 138:84-88,1990

83. Tulsi RS, Locket NA: Persistent trigeminal artery: An anatomical study. Aust N Z J Surg 55:397-402, 1985

84. Turkoglu E, Arat A, Patel N, Kertmen H, Baskaya MK: Anterior communicating artery aneurysm associated with an infraoptic course of anterior cerebral artery and rare variant of the persistent trigeminal artery: A case report and literature review. Clin Neurol Neurosurg 2011.doi.org/10.1016/j. clineuro.2010.12.009

85. Wismer GL: Circle of Willis variant analogous to fetal type primitive trigeminal artery. Neuroradiology 31:366-368, 1989

86. Wolpert SM: The trigeminal artery and associated aneurysms. Neurology 16:610-614,1966 